\title{
A dialética da globalização e a supressão do pré-capitalismo
}

Paulo Balanco ${ }^{1}$

Resumo: Este trabalho analisa as relações entre a globalização e o pré-capitalismo apoiado no referencial teórico marxista, do que decorre a vinculação da noção de globalização às transformações regulares da economia capitalista. Estas estão sintetizadas em uma base conceitual aqui denominada de dialética da globalização, correspondente a uma lei de desenvolvimento do capitalismo, permitindo, portanto, a extensão do conceito de globalização para toda a história desta sociedade. Deste modo, as leis de movimento e reprodução do capital impõem um permanente processo de mudanças, as quais, efetivadas sob o princípio da desigualdade, resultaram, no final do século XX, na manutenção do subdesenvolvimento e na supressão do pré-capitalismo.

Palavras-chave: capitalismo; globalização; pré-capitalismo.

\section{Globalization dialectics and the suppression of the pré-capitalism}

\begin{abstract}
This article analyzes the relations among globalization and the precapitalism based in Marxist theory. Globalization notion is linked to the regular capitalism's transformations. These are framed in a conceptual base denominated globalization dialectics. Like this, the movement laws and reproduction of the capital impose a permanent process of changes, driven under the principle of the

1 Professor do Curso de Mestrado em Economia e da Faculdade de Ciências Econômicas da Universidade Federal da Bahia. Doutor em economia pela UNICAMP. E-mail: balanco@ufba.br. Agradeço os comentários de contribuição a este texto oferecidos pelo professor Claus Germer (UFPR). Porém, é desnecessário afirmar que o conteúdo do artigo é de minha exlusiva responsabilidade.
\end{abstract}


inequality, resulting, in the end of the century $X X$, in the maintenance of the underdevelopment and in the suppression of the pre-capitalism.

Keywords: capitalism; globalization; pre-capitalism.

JEL: P10, P16, P17

\section{Introdução}

A reprodução do capitalismo, seja no plano nacional ou em sua amplitude internacional, somente acontece mediante um determinado princípio, ou lei econômica, conhecida entre os marxistas como lei do desenvolvimento desigual e combinado. Não é possível a este sistema econômico operar mediante uma diretriz de desenvolvimento homogêneo entre os espaços onde suas relações penetram, do que resulta a produção simultânea de desenvolvimento e subdesenvolvimento.

Marx, ao deduzir a lei geral da acumulação capitalista, ainda no Livro I de O Capital, mostra como essa economia, apresentando uma tendência para o decréscimo da lucratividade, atua mediante movimentos cíclicos indutores de saídas recuperadoras do lucro, tanto no plano interno quanto internacional, mas, ao mesmo tempo, produtoras da desigualdade.

Nesse sentido, o desenvolvimento do capitalismo ocorreu como uma totalidade, composta de partes "nacionais" interconectadas, das quais algumas, por um lado, possuiam o status, stricto sensu, de nações, paises e Estados capitalistas, enquanto outras, por outro lado, podiam ser consideradas como espaços pré-capitalistas. Conseqüentemente, a partir de determinado momento de sua história, a humanidade passava a viver sob este novo modo de produção, embora parte considerável da mesma não se encontrasse em esferas nacionais, ou espaços geográficos, estritamente capitalistas, mas, na verdade, sob controle destes.

Essa desigualdade surge como conseqüência da tendência inexorável de penetração das novas relações de produção em todos os espaços do planeta. Contudo, a efetivação dessa tendência aconteceu paulatina e diferenciadamente, no tempo e no espaço, desde a cristalização da Inglaterra como espaço nacional capitalista pioneiro.

Entretanto, mesmo sendo possível afirmar categoricamente que, como o fizeram Marx e Engels em O Manifesto Comunista, a partir de meados do século XIX se definira um mercado mundial capitalista, portanto, se constituíra uma estrutura sistêmica dotada de um centro e regióes periféricas dispostas em uma escala hierárquica, a relação desenvolvimento-subdesenvolvimento permaneceu dentro de um quadro cujas nações continuaram caracterizadas como capitalistas e pré-capitalistas. Seria 
somente a partir de meados da década de 1970 que as relações capitalistas ampliar-se-iam em intensidade suficiente para abolir o pré-capitalismo.

Transcorridas cerca de sete décadas do século XX, o capitalismo transformara-se intensamente relativamente àquele observado pelos olhos atentos de Marx quando da teorização levada a efeito em $O$ Capital. O prosseguimento do desenvolvimento capitalista nas décadas finais do último século, ao tempo em que se direcionava para o enfrentamento da crise estrutural de grande envergadura que atingiu o capitalismo ao final da expansão prolongada iniciada a partir da Segunda Guerra mundial, também exigiu a implantação de uma "unicidade" supressora de determinadas formas de diferenciação (Chesnais 2006). O esgotamento do período de acumulação dos "anos dourados" conduziu o capital a percorrer uma nova rota no sentido da recuperação das taxas de lucro e de acumulação que haviam recuado drasticamente. Abre-se, desta forma, um novo período na história do capitalismo, marcado por grandes transformações, entre as quais, destaca-se a introdução de novos mecanismos de integração dos espaços econômicos nacionais ao mercado mundial, o que acabou por abolir os últimos resquícios do précapitalismo. Por essa razão, pode ser afirmado que a globalização, em seu estágio mais recente, representa a inauguração de uma época na qual todos os espaços nacionais devem ser denominados pelo termo "nação capitalista".

Com isso, procura-se afirmar que o capitalismo concluiu um processo de expansão acompanhado da eliminação das relações pré-capitalistas subsidiárias. Esta afirmação, eleita como objeto de investigação, é analisada mediante o emprego de um arcabouço teórico-conceitual denominado dialética da globalização. Então, aceitando-se a tese que vincula a globalização às transformações do capitalismo, procurar-se-á deduzir as razões que confirmam a mudança da totalidade capitalista, de um conjunto constituído por nações capitalistas e pré-capitalistas para um conjunto formado apenas por nações capitalistas, mas qualificadas como desenvolvidas e subdesenvolvidas.

A aplicação particular das categorias do materialismo histórico ao estudo da sociedade capitalista condiciona a fixação dos pressupostos que permitem a elaboração da investigação aqui proposta, sobretudo no que concerne às suas leis de funcionamento e reprodução. Assim, podemos afirmar que o materialismo histórico pode ser empregado, considerando a utilização do método da abstração, em dois planos no sentido do estudo do desvendamento do capitalismo em sua trajetória cambiante. Num primeiro momento, apresenta-se como teoria útil para o entendi-mento do longo processo que desaguou na sociedade burguesa. Corresponde a um arcabouço conceitual que define o humano como 
um fundamento sócio-histórico próprio da atividade material praticada para a garantia da sobrevivência, a qual está sempre sujeita à mudança. Em um segundo momento, constatado o modo de produção capitalista como uma sociedade concreta decorrente dessa mudança, utilizase o método da Economia Política para caracterizar internamente o capitalismo como um processo e um sistema governado por determinadas leis econômicas formatadoras de sua endogeneidade.

Assim, além desta introdução, tendo em vista a elaboração de uma primeira referência teórica, discute-se na segunda seção os fatores determinantes das transformações históricas e a fixação do capitalismo. Na terceira seção elabora-se uma argumentação justificadora da relação entre a globalização e as transformações do capitalismo de acordo com a perspectiva da economia política formulada por Marx. Na quarta seção será desenvolvida a tese da supressão do pré-capitalismo no final do século XX e a manutenção do subdesenvolvimento. Finalmente, na quinta seção, alguns comentários são elaborados à guisa de conclusão.

\section{As premissas do desenvolvimento histórico e a totalidade capitalista}

Admitindo-se determinados cortes históricos, cada organização econômico-social passível de identificação ao longo da história pode ser interpretada mediante a aplicação do conceito de Modo de Produção (MP). O MP con-centra todos os elementos constitutivos da sociedade, ao tempo em que a produção, isto é, a economia, pode ser considerada como sua base in-fra-estrutural. De acordo com Preobrazhensky (1979: $52)$,

(...) O método do materialismo histórico é essencialmente um método de pesquisa altamente abstrato pois, no complexo indivisível do orga-nismo social - onde as relações diretas do processo de produção se misturam muito estreita-mente ao que se convencionou chamar, na terminologia marxista, "de superestrutura" - o marxismo começa a análise a partir do centro evolutivo de todas as modificações e de todo o movimento, quer dizer, a partir da economia, separando-a de todo o resto, num momento determinado do estudo, pela força da abstração.

Torna-se possível, então, estabelecer uma classificação de vários modos de produção, identificando-se as distinções entre os mesmos e, por con-seguinte, traçar a trajetória da evolução histórica e, ao mesmo tempo, introduzir a noção de continuidade histórica. A rigor, o MP não deve ser visto como uma expressão estática, já que a atividade produti- 
va possui uma propensão para a transformação permanente, o que lhe confere um conteúdo dinâmico em face da tendência das forças produti-vas a evoluir. Em certo sentido, pode-se dizer que são estas que tem a "iniciativa" no processo de transformação e, ao evoluírem, ou simplesmente se modificarem, exigem a necessidade de novas relações de produção, as quais estarão plenamente constituídas a ritmos e prazos previamente indefinidos. As relações de produção, assim transformadas, determinam uma nova base econômica (infra-estrutura) e, por conseguinte, em última instância, um novo MP. Segundo Eric Hobsbawm (1977: 22), verificamos que "(...) A teoria geral do mate-rialismo histórico requer apenas a existência de uma sucessão de modos de produção, e não a exis-tência de modos específicos, nem que haja uma ordem pré-determinada para esta sucessão. (...)”.

Assim, no plano da histórica concreta, ao examinar-se a história realizada, conclui-se que diferentes sociedades humanas, no que concerne às formas e os meios de produzir, estão "interligadas" entre si por meio de um pro-cesso de transformação no qual se destaca uma determinada "sucessão" de umas por ou-tras. Quer dizer, a história nos indica uma determinada linha de evolução com MP particulares sucedendo outros que se apresentam como seus precursores.

Em vista dessa dialética da transformação das relações de produção, um MP particular surge geneticamente ainda quando o MP precedente permanece existindo. Assim, novas relações de produção não surgem unilate-ralmente ou de forma "exterior", mas, somente dentro de um MP que esteja em funcionamento. (Marx 1987).

Por outro lado, para os propósitos deste estudo, deve ser esclarecido que as conclusões de Marx não foram derivadas da observação "(...) de um país considerado isoladamente, mas de uma seqüência de estruturas sociais universalizadas (escravidão, medievalismo, capitalismo)" (Trotsky 1977, Vol. 3: 1009). Entretanto, pode ser constatado que vários autores inverteram o ponto de partida metodológico, por conseguinte, confundindo o significado do MP com o conceito de nação/país.

Assim, se a hu-manidade ingressara na or-dem capitalista tendo como porta de entrada alguns países que se apre-sentaram como seus pionei-ros, os demais deveriam obrigatoriamente seguir o mesmo caminho. Enxer-gava-se uma lei de ferro independentemente dos fatos que apontavam que o novo MP já se disseminara e predomi-nava sobre o con-junto dos seres humanos a partir de determinada época.

Nesse sentido, para fazer jus às palavras de Marx, a formação social capitalista deve ser caracterizada como um sistema, reunindo o conjunto das nações em seu interior, mesmo que nem todas elas possam ser consideradas stricto sensu países capitalistas. Esse procedimento evita 
o risco de vincular o conceito de MP às localizações geográficas ocupadas pelos seres humanos. Explicando melhor, quer-se dizer que, uma vez que os traços capitalistas fundamentais tenham se concretizado em um determinado número de países até certa época, a partir daí qualquer outro país que experimentasse as novas relações de produção em seu próprio seio tomaria conhecimento de fundamentos já historicamente constituídos. Nesta situação, não se trata da reprodução da "construção" histórica do MP em novos espaços nacionais, mas, sim, da inserção histórica de um país em um MP já em funcionamento com todas as manifestações previsíveis relativas a um processo que tendia à universalização.

A propósito, para precisar o sistema capitalista de produção, seria necessário reconhecer que, atingidos determinados limites, as leis que o governam passaram a determinar a vida do conjunto dos países/nações como um todo. Por conseguinte, não resta dúvida que, completada a primeira metade do século XIX, embora grande número de países ainda permanecesse sob fundamentos pré-capitalistas, todas as suas transformações estruturais, daí para frente, seriam determinadas pelas relações capitalistas de produção tendo como fonte irradiadora aquelas nações que se apresentavam como as novas potências mundiais, ou os centros do sistema. Vale lembrar da Inglaterra como primeira nação central na era do capital e sua ação imperialista, além fronteiras, em busca de novos mercados e fontes de matérias-primas visando a reprodução ampliada interna de seu capital.

Se o marxismo conceituara, já na segunda metade do século XIX, o capitalismo como um MP de abrangência mundial, a vertiginosa expansão da sociedade burguesa até o final daquele século o obrigaria a caracterizálo sob outras condições. E, partindo-se dos fatos, isto implicaria que, ao iniciar-se o século XX, tornara-se indispensável incorporar ao marxismo o reconhecimento de que a formação social capitalista atingira uma determinada plenitude. Em outras palavras, alcançara a cristalização plena de suas formas sociais determinantes, exprimidas como, a saber, a propriedade privada dos meios de produção, o trabalho livre assalariado, o dinheiro e as relações de troca de valores-mercadorias, a inovação tecnológica e a concorrência como regularidades sintetizadas na forma de uma lei geral e um mercado mundial.

Como uma formação social plena-mente presente e dominante entre os seres humanos, o capitalismo opera, depois de cumpridas certas condições, como uma totalidade e não como um somató-rio de diversos países. Todavia, sob o pressuposto de que o capitalismo somente poderia ser caracterizado como uma economia mundializada quando um resultado quanti-tativo estivesse cumprido, isto é, quando um determinado número de países adentrasse integralmente ao universo burguês, então 
seria forçoso admitir que nas primeiras décadas do século XX o mercado mundial capitalista ainda inexistiria. Mas, o que prevalece é a totalidade, e não a soma das partes. Portanto, naquela altura um grande número de países ainda permanecia como colônias das grandes potências e vários outros que haviam adquirido independência política formal engatinhavam internamente no meio burguês, o que não impedia que a economia mundial capitalista estivesse já estruturada.

\section{A reprodução capitalista e a globalização}

A dedução teórica efetuada por Marx para apreender o movimento econômico interno da reprodução capitalista corresponde à aplicação de um método da economia política apoiado na dialética abstrato/concreto (Germer 200o). Acontece que, bem entendido, avaliando-se que o capitalismo deva ser interpretado metodologicamente como um MP equivalente a um sistema estabelecido de acordo com o movimento histórico acima descrito, deduz-se que uma de suas marcas fundamentais é a desigualdade entre as várias unidades nacionais que o compõe. Desigualdade combinada, permeada pela heterogeneidade e pela hierarquização entre forças nacionais dominantes e dominadas e por uma escala entre centros e periferias. Mesmo assim, são corpos de uma mesma estrutura, já que todos estão obrigatoriamente inter-relacionados dentro do mecanismo da lei do valor operando internacionalmente, isto é, no plano de um mercado mundial. Mesmo constando-se a enorme diferença entre o grau de desenvolvimento econômico entre os vários países, sem sombra de dúvidas, trata-se, em termos lógicos, já desde o final do século XIX, de um sistema completo. Mas, em outras palavras, sob outra perspectiva, apresenta-se como um sistema historicamente inacabado, que se reproduz dentro de si mesmo preservando essa desigualdade indispensável enquanto se desenvolve espacialmente.

Dessa forma, a história mostrava com nitidez que a evolução experimentada pelos países capitalistas pioneiros havia sido colocada de ponta-cabeça, podendo-se, portanto, concluir que a trajetória seguida pelos países avançados não poderia ser reproduzida pelos atrasados como a "imagem de seu próprio futuro". E, ainda mais, com o imperialismo surgia um bloqueio de dimensões quase intransponíveis para uma ampla modernização e industrialização nos chamados países subdesenvolvidos (Mandel 1995: 22).

Para entender este processo, faz-se necessário debruçar-se sobre as transformações permanentes exigidas pelo mecanismo de reprodução do capitalismo, as quais têm dois sentidos precisos: por um lado, decor- 
rem da ação das leis de funcionamento e reprodução do sistema. Por outro lado, resulta em permanente ampliação da ação das relações capitalistas através do planeta, ou do mercado mundial. Este, ao tempo em que é estabelecido pela lei do valor em sua ação internacional, também está sujeito a mudanças constantes, as quais, entre outros resultados, dizem respeito à incorporação continuada de regiões.

Na era do capital a humanidade passaria a experimentar uma evolução historicamente inédita. Inequivocamente, no lugar da coexistência de sociedades particulares distintas cujas relações de produção mantinhamse espacialmente restritas, o que denotava certa atomização, ou a conformação de diferentes tipos de sociedades presentes em um mesmo lapso de tempo, surge uma tendência à universalização de relações de produção específicas e historicamente determinadas (Balanco 1999).

Aqui podemos inserir o conceito de globalização. De certa forma, este conceito, embora passasse a ser utilizado recentemente para a interpretação das mudanças experimentadas pelo capitalismo, já se encontrava presente, mediante um determinando significado, desde os primórdios da investigação à respeito da natureza do capitalismo empreendida pelo marxismo. Por exemplo, há no Manifesto Comunista, obra editada por Marx e Engels em 1848, a caracterização do capitalismo como uma economia que apresenta uma lógica expansionista. Desta forma, aceitandose a globalização como equivalente a essa vocação do capitalismo, em vez de associá-la a uma determinada etapa do seu desenvolvimento, tornar-se-ia lícito denominá-la como um pressuposto necessário à vigência de seu mecanismo reprodutivo, definindo assim uma tendência endógena do capital à "mundialização". Por essa razão, acredita-se haver segurança suficiente para a afirmação da tese que associa a globalização ao capitalismo como um fenômeno presente desde seus primórdios (Balanco 1999; Sweezy 1997).

Temos, portanto, no Manifesto, a descrição de uma primeira noção de desenvolvimento do capitalismo, particularidade que distinguiria notavelmente este MP das sociedades precedentes, a qual, identificada com o fenômeno da globalização, deveria ser admitida como uma lei:

(...) A grande indústria criou o mercado mundial, preparado pela descoberta da América. $O$ mercado mundial promoveu um desenvolvimento incomensurável do comércio, da navegação e das comunicações. Esse desenvolvimento, por sua vez, voltou a impulsionar a expansão da indústria. E na mesma medida em que a indústria, comércio, navegação e estradas de ferro se expandiam, desenvolvia-se a burguesia, os capitais se multiplicavam e, com isso, todas as classes oriundas da Idade Média passavam a um segundo plano. (...).

A burguesia não pode existir sem revolucionar constantemente os instrumentos de produção, portanto as relações de produção, e por 
conseguinte todas as relações sociais. (...).

A necessidade de mercados sempre crescentes para seus produtos impele a burguesia a conquistar todo o globo terrestre. Ela precisa estabelecerse, explorar e criar vínculos em todos os lugares.

Pela exploração do mercado mundial, a burguesia imprime um caráter cosmopolita à produção e ao consumo em todos os países. (...) As indústrias nacionais tradicionais foram, e ainda são, a cada dia destruídas. São substituídas por novas indústrias, cuja introdução se tornou essencial para todas as nações civilizadas. Essas indústrias não utilizam mais matérias-primas locais, mas matérias primas provenientes das regiões mais distantes, e seus produtos não se destinam apenas ao mercado nacional, mas também a todos os cantos da terra. (...) (Marx \& Engels 1998:9,11)

O prosseguimento da análise a respeito da relação entre a globalização e o mercado mundial exige, porém, outro tratamento metodológico. Trata-se da abordagem econômica particularizada da economia burguesa, a qual remete à apreensão de seu mecanismo reprodutivo endógeno. Assim, no plano da teoria, a investigação da propensão à mudança do capitalismo no sentido da globalização demanda o emprego de um arcabouço constituído de categorias econômicas historicamente específicas, evidentemente, aquelas sintetizadas por Karl Marx em O Capital. ${ }^{2}$

Esta base teórica nos permite afirmar que as modificações concretas, que efetivam a história do capitalismo, coincidem com transformações no âmbito do mercado mundial. Decorre disso, então, que as diferentes facetas reveladas pela globalização ao longo do tempo representam novos estágios, ou novos quadros qualitativos do capitalismo, provocados pelas relações causais entre as categorias econômicas na forma de leis particulares deste sistema. Pode-se afirmar, dessa maneira, que há uma inequívoca relação entre as transformações do capitalismo e a atuação das leis gerais de movimento do capital.

Dentre outras, Marx localiza uma lei fundamental, que sanciona a relação entre lucro e acumulação. Trata-se da lei da tendência decrescente da taxa de lucro, cujo comportamento exibe a dinâmica da acumulação e, por conseguinte, orienta as trajetórias de evolução do sistema que resultarão nas metamorfoses que caracterizam os diferentes estágios atingidos pela globalização (Marx 1985-86, vol. IV:183).

Por sua vez, as flutuações da taxa geral de lucro e a constituição do movimento cíclico dessa economia dependem de alguns fatores, tais como a ação da lei geral da acumulação capitalista (as alterações na composição orgânica do capital e a modificação na distribuição do capi-

2 A respeito da alocação destas categorias na estrutura teórica de análise da reprodução capitalista, ver Marx ( 1985-86), especialmente vols. IV e V. Ver ainda Moseley (1998) e Mandel (1985). 
tal fixo e do capital circulante), o comportamento da taxa de mais-valia, o desenvolvimento da taxa de acumulação e o intercambio entre os departamentos de bens de produção e o departamento bens de consumo (Mandel 1985: cap. 1).

Acerca da teoria da taxa de lucro de Marx, devemos nos referir a algumas questões basilares: em primeiro lugar, ao processo de distribuição intra-setorial, inter-setorial e internacional do excedente. Em segundo lugar, à ação deste mecanismo posta pelo progresso tecnológico mediante o mecanismo da concorrência. Em terceiro lugar, ao movimento unificador da distribuição da mais-valia e da concorrência, colocado em ação pelos capitais individuais visando a realização de lucros extraordinários (Borges Neto 2004; Moseley 1998).

Enquanto a busca pelos superlucros desencadeia o movimento do capital por todo o mercado mundial, também a manifestação da fase descendente do ciclo econômico coloca em ação semelhante iniciativa. A fuga à uma situação de contração da taxa de lucro e da acumulação consubstanciam as ações típicas de contra-tendência. Entre estas se localiza, sobretudo, a redução do valor da força de trabalho e a contração da participação relativa dos gastos com capital variável no montante do capital global. Por essa razão, a expansão geográfico-espacial do capitalismo está intimamente ligada às possibilidades, onde quer que seja, de implementação de medidas relacionadas à mais-valia relativa e à maisvalia absoluta.

\section{Desigualdade combinada, supressão do pré- capitalismo e o novo mercado mundial}

Desde meados do século XIX até meados da década de 1970, a globalização apresentou particularidades intrínsecas à busca de determinados resultados da taxa de lucro. Uma argumentação bastante plausível, apresentada por Ernest Mandel (1985), dá conta de três momentos da história do capitalismo em que a procura por lucros extraordinários resultou em transformações na formatação e na abrangência das relações capitalistas no espaço do planeta e do mercado mundial.

Preliminarmente, no século XIX, essa iniciativa esteve relacionada ao desenvolvimento "regional" europeu, visto que as regiões agrícolas do velho continente surgiam, naquela época, como as mais adequadas para a introdução imediata das relações capitalistas, o que acabou acontecendo sob os auspícios do capitalismo concorrencial. O segundo momento corresponde à criação do sistema colonial pelas potências européias, ainda no século XIX, mas ainda ocorre no período do chamado "imperialismo clássico". Já o terceiro momento aconteceu no século 
XX, quando a perseguição aos lucros extraordinários passa a ser orientada pela tecnologia, sendo efetivada em regiões e ramos industriais tecnologicamente menos desenvolvidos, os quais podem se referir indiferentemente a paises avançados ou atrasados (Mandel 1985: cap. 3).

Simultaneamente, o movimento voltado para a expansão/recuperação da taxa de lucro, ao tempo em que produz a expansão do capitalismo, inevitavelmente cria e reproduz a desigualdade, a qual deve ser interpretada como um princípio fundamental deste sistema. Aditivamente, a desigualdade também pode ser interpretada por subdesenvolvimento ou atraso. Aqui, caracterizamos o subdesenvolvimento como fenômeno do espectro capitalista strictu sensu, o que remete a uma resultante inerente à natureza dessa economia. Isto quer dizer que a reprodução do capitalismo é necessariamente dual, portanto, dialética, porque ao tempo em produz desenvolvimento também cria o subdesenvolvimento. Nessa linha, o subdesenvolvimento deve ser entendido em termos absolutos e relativos, pois, à medida, por exemplo, que um país capitalista subdesenvolvido alcança níveis de desenvolvimento mais elevados em temos absolutos, continua apresentando internamente diferentes níveis de desigualdade ou de subdesenvolvimento relativo. O raciocínio se aplica à relação entre nações que passaram a compartilhar o mercado mundial como esferas capitalistas propriamente ditas. Todavia, por outro lado, quando nos referimos ao atraso, posiciona-se os países ainda pré-capitalistas relativamente ao universo capitalista dominante como regularidade no contexto do mercado mundial. Dessa forma, um país pré-capitalista comparado às esferas capitalistas, é considerado como uma região atrasada.

Então, o expansionismo, mediante a lógica capitalista, não pode ocorrer via a efetivação de uma homogeneização dos padrões materiais de existência das populações localizadas nas nações componentes da economia mundial. Pelo contrário, a transformação aqui denominada "dialética da globalização" não poderia ocorrer sem a presença da desigualdade como ponto de partida e de chegada.

Independentemente da relação espaço-tempo, há sempre um determinado quadro de subdesenvolvimento, latente ou em reprodução, sempre na iminência de reordenamentos e reorganizações. Periodicamente, essa marca indelével da globalização, a desigualdade, experimenta modificações qualitativas, resultando em mudanças substantivas no perfil da economia mundial. Continuamente, por um largo período de tempo, ocorreu regularmente a integração de regiões atrasadas (précapitalistas) ao mercado mundial, enquanto outras já desenvolvidas ingressavam numa era de decadência. 
Em síntese, a economia capitalista, vista como totalidade, portanto, tomada em uma abrangência para além do estado-nação, é governada pela lei do desenvolvimento desigual e combinado:

\begin{abstract}
(...) a desigualdade do ritmo, que é a lei mais geral do processus histórico, evidencia-se com maior vigor e com-plexidade nos destinos dos países atrasados. Sob o chicote das necessidades externas, a vida retardatária vê-se na contingência de avançar aos saltos. Desta lei universal da desi-gualdade dos ritmos decorre outra lei que, por falta de de-nominação apropriada, chamaremos de lei do desenvolvimento combinado, que significa aproximação das diversas etapas, combinação das fa-ses diferenciadas, amálgama das formas arcaicas com as mais modernas. Sem esta lei, tomada, bem en-tendido, em todo o seu conjunto material, é impossível com-preender a história (...) de todos os países chamados à civilização em segunda, terceira ou dé-cima linha (Trotsky 1977:25. Grifos no original).
\end{abstract}

Ao final do século XIX o capitalismo concluíra um primeiro estágio estrutural logicamente adequado à sua reprodução. Concomitantemente, no plano prático, ocorre o entrelaçamento indispensável - numa dimensão distinta daquela verificada na fase do capitalismo concorrencial - entre o capital industrial, o capital bancário e o capital comercial, viabilizando ordinariamente a centralização do capital como procedimento de maximização da lucratividade. Surgem unidades produtivas em grande escala, controladas por grupos econômicos, exprimindo o requisito da fusão das categorias funcionais do capital também na esfera da propriedade. A reprodução ampliada passa a ser garantida mediante um processo no qual a concorrência atomizada clássica é substituída pelo monopólio. Tem-se aqui a gênese e o desenvolvimento das grandes empresas transnacionais e um impulso para a utilização do Estado no sentido da viabilização da acumulação interna. A partir da conformação deste cenário, os países centrais cristalizam sua dependência do espaço econômico internacional para a reprodução do seu capital nacional.

Evidentemente, como já se frisou aqui, seria incorreto traçar um paralelo entre o desenvolvimento histórico dos países pioneiros do capitalismo, como, por exemplo, a Inglaterra, e o daqueles que surgiram na esteira do amadurecimento do capitalismo nas metrópoles. Nestas, as formas sociais e a criação de uma burguesia poderosa foi possível durante um processo particular que demandou séculos. De outro lado, as colônias e semi-colônias ingressaram na civilização capitalista mediante a condução das metrópoles, mas, se é difícil encontrar analogia no desenvolvimento entre esses tipos distintos de países, ao mesmo tempo, não é menos verdadeiro afirmar que existe uma "profunda conexão 
interna entre am-bos”. No início do século XX, Trotsky (s/d: 66-67) afirmaria o seguinte:

(...) para esses pedantes, a história de uma na-ção capitalista repete a história de outra com algumas divergências mais ou menos importantes. Hoje são incapazes de enxergar o processo unificado de desenvolvimento do mundo capitalista, que en-gole todos os países que encontra no seu caminho, que cria, das exigências nacionais e gerais do capitalismo, um amálgama cuja natureza não pode ser entendida mediante a aplicação de clichês, mas unicamente através da análise materialista. (...)

Com a consolidação do capitalismo como um sistema de abrangência mundial, sociedades "atrasadas", integradas a este universo, experimentam o impacto do contato com as mais "avançadas" e, como conseqüência, a mudança nas primeiras adquirem uma característica do atraso. Assim, a compreensão do desenvolvimento das sociedades atrasadas exige como ponto de partida analítico a relação recíproca entre estes dois tipos de sociedade.

Destarte, segundo Knei-Paz (1985), da ação da sociedade avançada sobre a atrasada resultam conseqüências traumáticas para esta última. Novas formas de produção econômica fragilizam sua tradicional hierarquia social e desagregam hábitos e costumes tradicionais. Podemos afirmar que tal resultado pode ocorrer tanto nos espaços coloniais, assim como naqueles países que já tenham conquistado formalmente sua independência política.

Mas, em que pese a impossibilidade das nações atrasadas reproduzirem o caminho percorrido pelas avançadas, as primeiras, por se desenvolverem a posteriori dos "pioneiros", deparam-se com determinadas vantagens quando perseguem o objetivo final. São os "saltos", que abreviam ou superam várias etapas, reduzindo o longo processo de desenvolvimento, com isso evitando o tempo histórico exigido para sua fixação. A redução do tempo de desenvolvimento, na verdade, expressa um processo diferente e uma maneira particular de desenvolvimento das sociedades atrasadas. O resultado é a construção prática de um modelo heterogêneo; este é materializado por uma integração entre as formas da sociedade avançada, face a ruptura com as formas arcaicas, e a formas antigas, que seguem existindo em escala apreciável. Conforma-se uma desigualdade latente, ou o produto histórico da atuação da lei do desenvolvimento desigual e combinado.

Dado o processo da desigualdade combinada, saltar etapas significa a criação de uma linha de desenvolvimento capitalista não linear, representando, por sua vez, o abandono de algumas formas de produção e a rejeição de certas formas sociais. Determinados agrupamentos sociais 
presentes nos países desenvolvidos não são constituídos, enquanto outros, característicos de experiências de desenvolvimento mais recentes, são cristalizados. Ao mesmo tempo em que ocorrências principais da sociedade tradicional perduram, resistem ou seguem dominando, surge um quadro global singular: “(...) absolutismo político, privilégios da aristocracia, uma vasta população camponesa, ao lado de uma indústria avançada, de uma urbanização, de uma classe operária, sem que de resto exista uma classe média com alguma importância econômica ou política. (...)" (Knei-Paz 1985: 179).

Este modelo aplica-se adequadamente ao desenvolvimento do capitalismo entre os séculos XIX e XX. Ao longo deste período a economia mundial fundamentou-se nas relações capitalistas como sua base econômica determinante, embora, dentro da totalidade das nações, tomadas individualmente, estivessem presentes, em diferentes momentos e magnitudes, como já afirmado, países pré-capitalistas ou semi-capitalistas. Mas, à medida que o tempo transcorria, as transformações da globalização tendiam a provocar a universalização das relações econômicas burguesas por todo o espaço do planeta. Portanto, seria perfeitamente lícito considerar-se, pressupondo-se a continuidade do capitalismo, o advento de uma situação na qual pré-capitalismo deveria desaparecer.

Em vista disso, considera-se que a expansão do capitalismo e a simultânea redução do pré-capitalismo exigem a presença de um processo de integração. Pode-se questionar o menor ou maior grau de autonomia que um país poderá desfrutar dentro deste ambiente, mas esta não pode ser confundida com uma atitude autárquica, infensa à influência da lei do valor atuando no mercado mundial.

Muito embora a integração logicamente se apresente como uma précondição para o desenvolvimento do capitalismo, sua efetivação não ocorre de forma espontânea, mas, antes de tudo, como conseqüência da iniciativa deliberada das nações e capitais dominantes mediante o emprego de métodos extra-econômicos na maior parte das vezes.

O desaparecimento gradativo do pré-capitalismo durante o século XX desenvolveu-se em dois períodos distintos, com resultados também diferentes. Assim, adotando-se critérios de periodização para classificar este processo, afirma-se que entre o inicio do século passado e a década de 1970 as relações pré-capitalistas foram substantivamente reduzidas, mas não totalmente eliminadas. Todavia, com as profundas transformações implementadas nas últimas duas décadas do século XX, quando a globalização adquire feições novas, o aprofundamento da integração do conjunto das nações ao mercado mundial colocaria um ponto final da coexistência entre capitalismo e pré-capitalismo. 
Ao se aproximar o final do século XIX a complexidade do mercado mundial já era relativamente profunda, de tal forma que a concorrência entre nações pelos espaços econômicos se tornara acirrada o suficiente para provocar uma recessão de grande envergadura que perpassaria a maioria dos países, capitalistas ou não. Desse modo, uma das particularidades dinâmicas mais notáveis do capitalismo, a instabilidade inerente às crises de superprodução, instalara-se definitivamente no mercado mundial.

A contração da taxa de lucro impôs, entre o inicio do século XX e o fim da Segunda Guerra, a entrada do capitalismo em um determinado período de globalização. Como elementos marcantes desta fase aparecem a elevação da composição orgânica do capital e suas contrapartes, a saber, a afirmação da grande empresa transnacional e o surgimento de novas formas de concorrência confirmadoras do monopólio. Nas relações entre nações e entre capitais emerge um "novo imperialismo", em que a presença dominante do monopólio impulsiona o processo da centralização, com o capital financeiro e a exportação de capitais desempenhando papéis decisivos, segundo uma nova conceituação elaborada pelos marxistas (Hilferding 1985; Bukharin 1986; Lênin 1979 \& Luxemburgo 1985).

Particularmente, este foi um período em que as empresas industriais e bancárias movimentaram capitais em grande monta dos países centrais para os países periféricos visando o estabelecimento da produção em face das vantagens que esta situação oferecia relativamente à efetivação de lucros mais elevados. Em vista disso, ocorre a aceleração da industrialização da periferia, configurando uma nova divisão internacional do trabalho, ao mesmo tempo impulsionando a destruição das relações pré-capitalistas internas. Nesta altura o sistema colonial, até então prevalecente sob condução das grandes potências, praticamente deixa de existir como fundamento estruturante do mercado mundial.

Uma etapa decisiva da globalização compreende o período entre as décadas de 40 e 70 do século XX. Ao final da Segunda Guerra inicia-se uma nova onda longa do capitalismo, sendo que sua fase expansionista atravessaria as três décadas seguintes. Além da prosperidade de longo-prazo, particularmente no centro do sistema, outros eventos e mudanças de grande expressão acontecem nesta fase, entre as quais podemos destacar a implantação da macroestrutura de Breton Woods e a transferência definitiva da hegemonia no mundo capitalista das mãos da Inglaterra para as dos EUA. Contudo, essa "golden-age" não apagou a marca característica do mercado mundial, qual seja, a desigualdade, o subdesenvolvimento e o atraso.

Em virtude do aprofundamento da integração dos países atrasados ao mercado mundial, uma das principais mudanças observadas diz respei- 
to a aquisição por parte dos países capitalistas subdesenvolvidos e atrasados do estatuto de, também, produtores de bens acabados a preços de monopólio. Ainda por volta dos anos 70 o mercado mundial confirmava um cenário de relações econômicas capitalistas marcadas pela desigualdade, subdesenvolvimento e atraso, mas, ainda, composto, mesmo que limitadamente, por um conjunto de nações capitalistas e précapitalistas.

Apesar da portentosa propagação das relações capitalistas pelos quatro cantos do planeta durante os primeiros 70 anos do século XX, permaneciam resquícios significativos do pré-capitalismo no interior da economia internacional enquanto totalidade. O ponto de inflexão que levaria a supressão do pré-capitalismo está relacionando ao esgotamento da fase expansiva da onda longa iniciada após o fim da Segunda Guerra. O fim da prosperidade, por seu lado, está baseado na ação da lei da queda tendencial da taxa de lucro, que, nos anos 70, confirmava drasticamente sua funcionalidade na operacionalização da trajetória cíclica da economia burguesa. A redução da taxa geral de lucro inicia uma nova fase, marcada por crises recorrentes, acompanhadas por acirramento da instabilidade e com forte presença de estagnação, inflação e desemprego ${ }^{3}$ (Duménil \& Lévy 2003b).

As atitudes colocadas em prática desde então com a finalidade de reversão da taxa de lucro aconteceram com a introdução de grandes transformações na estrutura de funcionamento do capitalismo contemporâneo. Estas podem ser sintetizadas, em linhas gerais, como medidas voltadas para a desvalorização do trabalho mediante amplos processos de reestruturação produtiva, inovação tecnológica e financeira, desregulamentação e aprofundamento da integração econômica dos países ao núcleo orgânico do sistema.

Além dos resultados deletérios que produziu, a crise iniciada nos anos 1970 abriu caminhos em direção oposta. Determinado número de paises asiáticos, até então mergulhados no atraso pré-capitalista, viu surgir uma nova industrialização. Portanto, após cerca de três décadas de políticas econômicas que principalizavam o pleno-emprego, esta grave crise levou o capitalismo a reconstruir o exército de reserva de trabalhadores nos países centrais e, simultaneamente, a lançar mão deste mesmo exército historicamente constituído desde longa data nos países atrasados.

As novas formas de integração econômica que surgem na esteira dessas mudanças introduzem nova característica à globalização, denotando uma nova combinação de livre-comércio com as vantagens das desigualdades acentuadas entre os países. Em termos pragmáticos, surgiram as chamadas "estratégias de mercado" associadas às "estratégias de racionalização da produção", resultando no afloramento de novas 
formas de gestão e modos de organização dos grupos empresariais, assim como novos mecanismos da distribuição espacial da produção (Chesnais, 1996:129).

Nesse sentido, pode ser afirmado que o mercado mundial é reorganizado sob novas condições. Surgem novos concorrentes em regiões onde antes o imperialismo exercia plena dominação. Um exemplo fortemente ilustrativo desse novo cenário diz respeito aos papéis agora exercidos por dois novos atores de grande relevo, a China e a Índia, no contexto da reprodução capitalista mundial. Estes são reintegrados na esfera da valorização planetária capitalista, porém, esse processo ocorre em ruptura com as relações políticas vigentes à época do imperialismo clássico. No "novo capitalismo" esses dois grandes países foram elevados à categoria de núcleos de acumulação de primeira linha, função que os induzem a atuarem como "re-colonizadores" em virtude, entre outras manifestações, da entrada dos mesmos na disputa por matérias-primas. (Chesnais 2007).

Deste modo, o capitalismo passa a atuar em todos os espaços do planeta mediante a aplicação de um novo paradigma tecnológico, em boa medida relacionado à nova importância qualitativa do trabalho na reprodução do capital. Simultaneamente, também introduz mudanças significativas do papel do Estado na economia como peça integrante do novo padrão popularizado doutrinária e ideologicamente de "globalização", ou, em termos conceituais mais formais, como dinâmica neoliberal (Dumènil \& Lévy 2003a). Para Chesnais (2007:50-51, grifos no original), nessa dinâmica

(...) O regime internacional da mundialização do capital reforçou em todos os cantos os direitos da propriedade e os mecanismos da apropriação fundada na exploração do trabalho ou nas punções de rendas. A transição acelerada ao capitalismo na China reforçou o processo no plano global. A posição social e o poder político de todas as oligarquias foram reforçados pela mutação ordenada do aparelho do Partido Comunista Chinês. Em setores precisos que denominamos hoje de "as grandes economias do sul”, bancos e serviços financeiros, agro-indústria, minas e metais de base, constata-se uma acentuação da centralização e da concentração do capital análoga àquela dos "paises do norte". Nos quatro-cantos onde a formação de oligarquias "modernas" se deu conjuntamente com fortes processos endógenos de acumulação financeirizada e de valorização de "vantagens comparativas" conforme a necessidade das economias centrais - vantagens naturais para os produtos de base e/ou exploração de mão de obra industrial bem barata - estas foram integradas ao funcionamento do regime internacional da mundialização (...)

(...) A necessidade para o capital americano de se opor aos efeitos da baixa tendencial da taxa de lucro foi tão mais forte que os acionistas e os mercados das bolsas encontraram possibilidades de impor suas exigências em matéria de níveis e de repartição de lucros. Essa baixa 
exigia instituições que permitissem uma equalização rápida da taxa de lucro. O neoliberalismo as criou. As transferências de investimentos das atividades com perda de rentabilidade para aquelas cuja rentabilidade aumentava, produziu efeitos mais importantes sobre a taxa de lucro no plano transnacional que no plano doméstico. Esta é a explicação do caráter massivo dos IED's e da terceirização internacional dos Estados Unidos para a Ásia, a China e a Índia em primeiro plano. Assim fazendo, os Estados Unidos facilitaram a via aos países que estão se transformando em seus grandes rivais, notadamente a China que teria necessitado, sem dúvida, de vinte anos para realizar o salto adiante industrial, através de seus próprios meios (...)

Como pode ser visto, estes procedimentos não poderiam ser efetivados com a permanência dos resquícios pré-capitalistas dentro da economia internacional. As novas exigências da integração econômica, entendidas como pré-requisitos fundamentais para a recuperação da lucratividade, impuseram uma nova formatação da divisão internacional do trabalho. Nesta, as funções da maioria esmagadora dos países devem estar assentadas em relações capitalistas stricto sensu. Portanto, ao findar o século XX, a universalização do atual modo de produção, que antes abarcava um conjunto de países capitalistas e pré-capitalistas, compreendia um conjunto de países, mais do que nunca mantidos sob a regra da desigualdade, os quais devem agora ser denominados genericamente países capitalistas, mas sob os adjetivos desenvolvidos e subdesenvolvidos. Esta é a marca indelével posta pela globalização nesta última fase ainda em curso.

\section{Conclusões}

A agressividade do capital no último quarto de século, procurando recompor as taxas de lucro deprimidas como conseqüência do fim do período de acumulação prolongado inaugurado no fim da Segunda Guerra, veio acompanhada de um amplo e profundo processo de transformação da economia capitalista mundial. Lançando mão do desenvolvimento analítico aqui efetivado, denominou-se este período como uma etapa particular da globalização experimentada pelo capitalismo ao longo de sua história.

Foi exatamente neste período, decorrente do processo acima mencionado, que as poderosas forças do capital levaram a efeito a conclusão do processo de integração das regiões pré-capitalistas remanescentes ao mercado mundial e diretamente ao mecanismo reprodutor deste sistema em condições estritas. Porém, antes da eclosão da crise dos anos 1970, o capitalismo havia percorrido uma trilha de desenvolvimento na qual a penetração nas regiões atrasadas (pré-capitalistas) também se 
processara como comportamento regular próprio da sua reprodutibilidade.

Afirmou-se aqui também que as transformações capitalistas podem ser equiparadas à globalização, que não é outra coisa senão a concretização da tendência e da necessidade do capitalismo à expansão geográfica de suas relações fundamentais. Assim, tanto em condições caracterizadas pela prosperidade, quanto nos períodos em que experimenta situações recessivas, o capitalismo continua a se expandir e a modificar sua própria totalidade. Portanto, nada mais ordinário que a supressão definitiva do pré-capitalismo, ocorrendo no último quarto do século $\mathrm{XX}$, tenha sido produzido em condições sobejamente difíceis para manter seu mecanismo reprodutivo operando num ambiente em que a crise tende a se perpetuar.

Nesse sentido, se admitirmos que a globalização, de per se, pode ser equiparada a uma lei estrutural do capitalismo, portanto, também acionada para a viabilização dos elementos contrariantes da queda da taxa de lucro, poder-se-ia caracterizar o atual processo de mudanças, na qual está presente a incorporação ampla das regiões antes précapitalistas ao mercado mundial, como uma reação equivalente àquelas ocorridas em períodos passados como movimentos de contra-tendência.

Por fim, é necessário afirmar que este mesmo processo não pode ser consolidado sem que o capitalismo preserve um de seus fundamentos estruturais mais importantes, qual seja, a desigualdade. Assim sendo, enquanto esse sistema elimina os espaços pré-capitalistas, concomitantemente mantém e aprofunda o subdesenvolvimento. Somente diante de tal resultado seria possível afirmar que a homogeneização, representada pela disseminação generalizada das relações sociais burguesas, tem como contrapartida uma totalidade heterogênea, a qual devemos denominar de capitalismo desenvolvido e capitalismo subdesenvolvido.

\section{Referências}

BALANCO, Paulo (1999). As transformações do capitalismo: elementos teóricos para a composição de uma dialética da globalização. IV Encontro Nacional de Economia Política, Porto Alegre, Anais (CD-ROM), 1 a 4 de junho.

BORGES NETO, João Machado (2004). “As várias dimensões da lei do valor”. Nova Economia, Belo Horizonte, 14(3): 143-158.

BRENNER, Robert (1998). "The economics of global turbulence: a especial report on the world economy, 1950-98". New Left Review, $\mathrm{n}^{0} 229$. 
BRENNER, Robert (2003). O boom e a bolha: os EUA na economia mundial. Rio de Janeiro, Record.

BUKHARIN, Nicolai (1986). A economia mundial e o imperialismo. São Paulo, Nova Cultural.

CHESNAIS, François (2006). "A mundialização do exército industrial de reserva”. O Comuneiro - Revista Electrónica n. 3. URL: http:// www.ocomuneiro.com.

CHESNAIS, François (2007). "Da noção de imperialismo e da análise de Marx do capitalismo: pré/visões da crise". In NÓVOA. Jorge (Org.). Incontornável Marx. Salvador, EDUFBA; São Paulo, Editora UNESP, pp. 47-82.

CHESNAIS, François (1996). A mundialização do capital. São Paulo, Xamã.

DUMÈNIL, G. \& LÈVY, D. (2003a). Neoliberal dynamics - imperial dynamics (preliminary draft). III Colóquio Latino-americano de Economistas Políticos, Buenos Aires, Anais.

DUMÈNIL, G. \& LÈVY, D. (2003b). "Superação da crise, ameaças de crises e novo capitalismo". In CHESNAIS. François. et alli. Uma nova fase do capitalismo? São Paulo, Xamã, pp. 15-42.

GERMER, Claus (2000). Contribuição ao entendimento do método da economia política, segundo Marx. Curitiba, UFPR, 2000.

HILFERDING, Rudolf (1985). O capital financeiro. São Paulo, Nova Cultural.

HOBSBAWM, Eric (1977). "Introdução". In: MARX, Karl (1977). Formações econômicas pré-capitalistas. Rio de Janeiro, Paz e Terra.

KNEI-PAZ, Baruch (1985). “Trótski: revolução permanente e revolução do atraso". In HOBSBAWM. Eric, J. et al. (orgs.). História do marxismo. Rio de Janeiro, Paz e Terra, vol.V.

LENIN, Wladimir (1979). Imperialismo fase superior do capitalismo. São Paulo, Global.

LUXEMBURG, Rosa (1985). A acumulação do capital. São Paulo, Nova Cultural.

MANDEL, Ernest (1985). O capitalismo tardio. São Paulo, Nova Cultural.

MANDEL, Ernest (1995). Trotsky como alternativa. São Paulo, Xamã.

MARX, Karl (1987). Marx. São Paulo, Nova Cultural, vol. I.

MARX, Karl (1985-86). O capital - crítica da economia política. São Paulo, Nova Cultural (Os Economistas), vols. I - V.

MARX, K. \& ENGELS, F. (1998). "Manifesto do Partido Comunista”. In REIS FILHO, Daniel Aarão (org.). O manifesto comunista 150 anos depois. Rio de Janeiro/Contraponto, São Paulo/Fundação Perseu Abramo.

MOSELEY, Fred (1998). “A teoria econômica de Marx: verdadeira ou falsa? Uma resposta marxista à análise de Blaug”. Revista ANPEC. , nº 4.

PREOBRAZHENSKY, Evgen (1979). A nova econômica. Rio de Janeiro, Paz e Terra. 
SWEEZY, Paul (1997). "More (or Less) on Globalization". Montlhy Review, Volume 49, number 4, september.

TROTSKY, Leon (1977). A história da revolução russa. Rio de Janeiro, Paz \& Terra, Vols. I e III.

TROTSKY, Leon (s/d). A revolução de 1905. São Paulo, Global. 